\title{
25 Research Square \\ Remote Online Exams Anxiety during the COVID-19 \\ Crisis: A Cross-Sectional Study among Medical Students
}

\section{Haniye Mastour}

Assistant Professor of Educational Technology, Department of Medical Education, Faculty of Medicine, Mashhad University of Medical Sciences, Mashhad, Iran

\section{AmirAli Moodi Ghalibaf}

Student Research Committee, Faculty of Medicine, Mashhad University of Medical Sciences, Mashhad, Iran

Shabnam Niroumand ( $\nabla$ shabnamniroomand@yahoo.com )

Assistant Professor of Community Medicine, Department of Community Medicine, Faculty of Medicine, Mashhad University of Medical Sciences, Mashhad, Iran

\section{Research Article}

Keywords: Test Anxiety, Medical Education, Medical Student, Virtual Education, Online Exam, EAssessment, E-Learning, Sarasons's Test Anxiety Scale, COVID-19

Posted Date: January 25th, 2021

DOl: https://doi.org/10.21203/rs.3.rs-144112/v1

License: (9) This work is licensed under a Creative Commons Attribution 4.0 International License. Read Full License 


\section{Abstract}

Introduction: Assessment and evaluation are major parts of the medical curriculum which motivate students to study, being a competent physician, and achieving the medical education eligible goals. Medical students, especially at undergraduate levels, experience a significant amount of anxiety due to frequent exams. Meanwhile, the coronavirus disease 2019 disaster forced higher educational institutes all over the world to adopt distance learning. So remote online exams were used as a kind of assessment that can lead to new paradigms.

Methods: This cross-sectional study was planned to assess the remote online exams anxiety during COVID-19 Pandemic by analyzing test anxiety categories among basic science and pre-clinical medical students and its correlation between genders in the School of Medicine, Mashhad University of Medical Sciences, Iran, in 2020. Data collection tools were Demographic Questionnaire and Sarasons's Test Anxiety Scale. Descriptive statistics (mean, percentages) and analytical statistics (t-test and one-way ANOVA) were used to analyze the data with SPSS version 11.5.

Results: 290 medical students in basic science and pre-clinical courses were enrolled. $194(66.4 \%)$ of participants were female and 177 (60.6\%) were in basic sciences course. The prevalence of mild, moderate, and severe anxiety was $27.9 \%, 36.9 \%$, and $35.2 \%$ respectively. The difference in the mean and SD of anxiety score in basic sciences students and pre-clinical students was not statistically significant (Pvalue $=0.26$ ), yet the results indicated that the level of anxiety in females $(19.07 \pm 7.11)$ is significantly higher than males (14.44 \pm 7.15) (Pvalue<0.001).

Conclusion: According to the current study, there is a critical need to take steps to recommend stress management techniques and bring reforms in E-learning and E-assessment systems to lower the anxiety in medical students while providing a stable and reliable electronic exam environment can be helpful.

\section{Introduction}

Anxiety is defined as a mental phenomenon which is experienced by all of the humans during their life. Although, anxiety is the cause of our inappropriate performance and many mistakes, but a normal level of anxiety seems to be necessary for hardworking and being responsible $(1,2)$. Among types of anxiety, test anxiety is a psychological response, consist of worry, stress, emotionality, lack of confidence, fear of failure, and interference that can be experienced by an individual before, during, and after an exam or similar situations (3). Like the other kinds of anxieties, a certain level of the test anxiety could be push students to work harder and learn better, but mostly the high level of this bad feeling causes psychological distress, low performance, underachievement, demotivation, etc. in the students (4). Personal factors like insufficient studying and defects in test skills are not the only causes of test anxiety, and the organization's performance could cause this (5). Previous studies investigated that medical students, in comparison with other students, had a higher level of test anxiety because of their tendency to have a higher level of knowledge and professional skills (6). 
Today online learning and electronic assessment, learning and examining through virtual platforms, is become common in the world and in many fields take a place of the traditional face-to-face learning and examining (7). In addition to the benefits of online examination, such as cost and time effectiveness, the disadvantages like the security of the exam, availability of the required instruments, and the effect of this method on completely learning of the topic is a place of discussion (8). All over the world, universities and higher educational institutions have been closed, fully or partially, to limit the expansion of COVID-19 infection. Online examination had become common and popular for many years, but the emergence of the new coronavirus disease (COVID-19) notified its importance and consequently has forced us to use it more than before (9). Although, many educational institutes were approved E-exams, but these processes were usually based on in-campus online exams in which students receive technical support to make the exam environment more suitable; unfortunately, these supports are not completely possible in remote testing now. Mashhad University of Medical Sciences (MUMS) has adopted virtual education by the initiation of COVID-19 crisis since mid-February 2020. Moreover, remote online exams were launched as an assessment approach to investigate students' academic performance during the current situation. Many studies have been done to determine the anxitey level of students, especially medical students, during exams up to now and most of these studies, from all over the world, indicated a high levels of this phenomenon in medical students (10). Some studies measured the test anxiety level too high, which performing serious interventions were considered necessary $(10,11)$. However, by the expansion of COVID-19, the learning and evaluation of the medical students shifted to be online more than before. It should be noted that COVID-19 pandemic, on its own, makes people anxious and stressed and medical students are no an exception. It seems that this examination procedure, online exams, needs further evaluations to find its advantages and disadvantages. Therefore, we performed this study to determine the test anxiety level of the online examinations in medical students during the COVID-19 pandemic.

\section{Methods}

This cross-sectional study was done on medical students of Mashhad University of Medical Sciences which trained virtually in second semester of 2020. All medical students who were trained in basic sciences and pre-clinical courses during the second trimester of 2020 were eligible to participate in the study. According to the Murgan calculation method and regarding the whole number of medical students in basic sciences and pre-clinical courses, total sample size was determined 280 eligible students.

The instrument used in this study, was a 37-item Sarason's Test Anxiety Scale. This instrument was produced by Sarason in 1957 and has 37 items in "Yes and No" answers. The instrument reliability and validity were confirmed by Yazdani and the Cronbach a was 0.88 (12). Due to the proper psychometric properties and having the standard cut points for this instrument, it is widely used in assessing test anxiety. This self-fulfilling questionnaire assess a student's mental states and physiological experiences during, before and after the exam. In order to calculate the score of the questionnaire, each "yes" answer is awarded one point. Questions number 3, 15, 26, 27, 29 and 33 should be recoded because of their inverse concept. An individual's test anxiety score is obtained by adding all scores. A higher score 
demonestrates more test anxiety and the student is placed in one of these three categories according to the score obtained:

- Mild anxiety: Score 12 and lower;

- Moderate anxiety: Score 13 to 20;

- Severe anxiety: Score 21 and higher.

The URL of electronic version of the questionnaire was made available to all students through their virtual class groups in messaging apps like WhatsApp or Telegram. Before the start of final exams of second semester, the questionnaire was available to answer for one week and then closed. The aim of the study was illustrated to students in the first part of the questionnaire. Students were reassured about the anonymity and confidentiality of the questionnaires.

The data were analyzed using SPSS version 11.5. The scores of perceived test anxiety were calculated. The number and frequency of medical students who were anxious before their exams according to anxiety categories and also their demographic variables were assessed. According to the results of kolmogorov-smirnov test to evaluate normality condition, Student $\mathrm{T}$ test or Mann Whitney $\mathrm{U}$ test were used to investigate the differences between two groups and one-way ANOVA or kruss-calwallis test for more than two groups. In all analysis $p$ value $<0.05$ was considered as statistically significant.

\section{Results}

In this cross-sectional study 290 medical students in basic science and pre-clinical course were enrolled. None of the students have mentioned the previous experience of the electronic test so far. $66.4 \%$ of participants were female and most of them were in basic sciences course. Details are shown in Table 1. 
Table 1

Demographics characteristics and anxiety categories of participants

\begin{tabular}{|lll|}
\hline Variables & & N (\%) \\
\hline Gender & Female & $194(66.4)$ \\
\cline { 2 - 3 } Age & Male & $96(32.9)$ \\
& $=<20$ & $163(56.2)$ \\
\cline { 2 - 3 } Residential Status & $>20$ & $127(43.8)$ \\
\cline { 2 - 3 } & Native & $157(54.1)$ \\
\hline Course of Study & Non-native & $133(45.9)$ \\
\cline { 2 - 3 } & Basic Sciences & $177(60.6)$ \\
Anxiety Category & Mre-Clinical & $113(38.7)$ \\
\cline { 2 - 3 } & Mild & $81(27.9)$ \\
\cline { 2 - 3 } & Moderate & $107(36.9)$ \\
\cline { 2 - 3 } & Severe & $102(35.2)$ \\
\cline { 2 - 3 } & &
\end{tabular}

Anxiety categories frequencies in basic science course and pre-clinical course was demonstrated in Table 2.

Table 2

Anxiety categories according to different variables

\begin{tabular}{|lllll|}
\hline & \multicolumn{2}{l}{ Anxiety Category } & P.Value \\
\cline { 2 - 4 } & mild & moderate & severe & \\
\cline { 1 - 4 } Basic Science & $51(28.8 \%)$ & $67(37.9 \%)$ & $59(33.3 \%)$ & 0.36 \\
\cline { 1 - 4 } Pre-Clinical & $30(26.5 \%)$ & $40(35.4)$ & $43(38.1 \%)$ & \\
\hline Male & $44(45.8 \%)$ & $33(34.4 \%)$ & $19(19.8 \%)$ & $<0.001$ \\
\hline Female & $37(19.1 \%)$ & $74(38.1 \%)$ & $83(42.8 \%)$ & \\
\hline
\end{tabular}

Table 3 shows the mean and SD of anxiety score in basic sciences students and pre-clinical students. The differences of anxiety score in different genders also was illustrated in Table 3. 
Table 3

The mean score of anxiety in different courses and genders of individuals

\begin{tabular}{|lll|}
\hline Course & Mean \pm SD & P.Value \\
\hline Basic Science & $17.15 \pm 7.55$ & \multirow{2}{*}{0.26} \\
\cline { 1 - 2 } Pre-Clinical & $18.15 \pm 7.26$ & \\
\cline { 1 - 2 } Male & $14.44 \pm 7.15$ & $<0.001$ \\
\cline { 1 - 2 } Female & $19.07 \pm 7.11$ & \\
\hline
\end{tabular}

\section{Discussion}

The paradigms of structure, delivery, and medical education, like many others, have been affected by the COVID-19 pandemic. Therefore, undergraduate and graduate medical education in order to adapt to the conditions of this crisis have inevitably changed their approaches to virtual education. Observance of physical distance and health protocols has led to the implementation and application of remote electronic technologies in medical education and assessment. However, it is important to note that the effective use of these technologies in the first step requires an accurate understanding of their features, and in the next step, knowledge about these platforms and their opportunities and limitations for those who involved in medical education is essential (13).

Exam anxiety is one of the common problems of medical students that has been considered in various studies and many reports have been provided in this regard (14-16). The objective of this study was to assess levels of online exam anxiety among medical students in the Mashhad School of Medicine, one of the top five medical schools in Iran in 2020. Findings showed that the prevalence of mild, moderate, and severe anxiety was $27.9 \%, 36.9 \%$, and $35.2 \%$ respectively. In addition, the difference in test anxiety among the students of basic science and Pre-clinical was not significant, yet the results indicated that the level of anxiety in females is significantly higher than males.

Students typically experience multiple stressors from a variety of sources. The challenges that may be encountered in controlling the situation can lead to various psychological and emotional pressures (17). The main concerns among students that lead to anxiety are about their academic achievements, success, and post-graduation plans (18). Studies have shown that medical students experience anxiety in different ways in various stages of education (19). Medical education is more stressful than other disciplines, and that anxiety is one of the most common challenges among medical students (16). However, excessive anxiety can weaken students and, if not properly managed, can lead to impaired performance, lack of motivation, reduced academic achievement, and psychological problems (20). Paying attention to the issue of anxiety in medical students requires more care because of the important consequences it can have $(21,22)$. 
Evidence suggests that medical students become anxious before and during exams (23-26) and moderate test anxiety is usually observed in them (27). Quek et al. nalyzed data from 40348 medical students while studying 69 studies. Findings showed that the prevalence of anxiety in medical students was $33.8 \%$ in global and among them the highest rate of anxiety in medical students was from the Middle East and Asia (21). The other study reported average anxiety score as 12.86 among the participants (28). Latas et al. investigated test anxiety of medical students of Belgerad University of Medical Sciences and stated that most of these students suffered from test anxiety (27). Jadoon et al. announced anxiety level of medical students as $28 \%$ (29). Darabi et al. declared that $66 \%$ of students experienced moderate and severe anxiety (30). Results from a study by Tsegay et al. showed that in Ethiopia test anxiety dedicates a significant percentage of medical students $(52.30 \%)$ and the findings suggest that between test anxiety and factors such as gender, being a freshman, oral exam, level of social support and the existence of psychological problems there is a significant relationship (31). Therefore, the amount of test anxiety that causes the problem, which the results of studies indicate is common among medical students, should be given more attention. Outcomes of this study are consistent with other researches that has declared medical students' high prevalence of test anxiety.

In the study of Simran et al., the mean of anxiety prior to examination was $70.89 \pm 14.55$ in females and $63.91 \pm 11.73$ in males, as the results show, female students experienced more test anxiety (16). In our study, gender was also observed as an influential factor in the level of test anxiety, which led to significant differences. The findings of many studies indicate that the gender factor leads to a significant difference in the level of test anxiety and in general female students experience more anxiety before the test compared to male $(27,32-39)$. It is said that the probable reason for the difference in test anxiety levels in females compared to males could be due to the increase in women's emotional vulnerability (40). Some studies have justified differences in women's self-confidence and anxiety levels with competency issues compared to men (41). Considering the factors that increase test anxiety in medical students, it has been reported that females experience memory loss in exams and as a result, they have to make more efforts to memorize than males (35). Nevertheless, some studies showed no significant difference between mean score of anxiety and gender $(21,28)$.

On the other hand, findings indicated that the difference in test anxiety among the students of basic science and Pre-clinical was not statistically significant; consistent with some other studies which did not report a significant relationship between test anxiety and academic year $(21,28,42,43)$. Although, a previous study of medical students in the basic sciences reported that $50 \%$ of students suffer from severe test anxiety (44).

Consistent among the studies, it was proven that assessment and measurement can lead to stress or anxiety. There may be a relation between test anxiety and dysfunction (38). Problematic test anxiety rates of 25 to $40 \%$ in undergraduate medical students can have devastating effects on academic performance and student achievement (31). Anxiety can lead to mental distress and negatively affect students' cognitive performance and learning (45). Studies have reported that if medical students learn skills such as time management, then applying these skills can help reduce anxiety and lead to improvement of their 
academic performance (46). Studies have recommended that students should have the opportunity to experience more formative tests so that they receive meaningful feedback during these continuous assessments and are guided to correct their deficiencies and thus can improve their learning (47).

A survey conducted by the International Association of Universities (IAU) of higher education institutions around the world found that more than $90 \%$ of them have switched to virtual education or are developing distance education to continue the teaching and learning processes (37). Despite the notion that $\mathrm{E}$ learning is of lower quality than face-to-face classroom, emerging studies offer something opposite (48). However, this is obvious that the migration to virtual education has posed significant concerns for universities and educational institutions, and in the meantime, the implementation of assessment and evaluation processes in the form of remote online exams has faced major challenges (49). Currently, although online exams can be a useful topic for distance learning with the possibility of providing realtime feedback, which seems challenging due to the increasing number of students for faculty members $(50,51)$, but time constraints are still a concern in E-exams (52) and it is even more worrying if the examinations are held remotely. There is another concern, the navigation protocol and policy adopted to move between exam questions can be confusing and time consuming, leading to more stress for students. For example, this navigation policy, in which students are not able to return to the previous question, is not favorable for them. Other factors reported by students include that the exam questions do not match the content taught, and this affects their grades. This can be due to the unpreparedness of students and educators to participate in E-learning and virtual education. Academic dishonesty was another issue that was noted, especially by students who believed that remote E-exams were more stressful (37). Totally, digital technology in all areas has improved the efficiency of processes and the effectiveness of systems, and obviously higher education is no exception (53). Learning and teaching is transforming away from the conventional lectures. In the current context, this issue is exacerbated by the COVID-19 crisis (54), students are transitioning from face-to-face examinations to the remote online exams. However, with students' frequent use of online exam platforms, their anxiety decreased. However, it is recommended that this information be disclosed to students in order to change their perceptions and reduce anxiety during the online test (53). While the researches related to online examinations are in progress, discussions at the educational level still need to be completed and it is necessary that the study will continue to find and share experiences.

\section{Conclusion}

Despite the limitations of a cross-sectional study, the findings of this study provide new evidence of remote online exams during the COVID-19 pandemic in medical education. This pandemic has provided a rapid growth in E-learning and virtual education. Engaging online learning environments and electronic assessment platforms may replace conventional methods. Training programs have responded extensively to changes in education during the COVID-19 crisis, and these actions should be evaluated and revised as a guide to educational institutions and international standards in order to draw the future of virtual education as effectively as possible. What is certain is that medical students are valuable human resources in the future of our medicine, so monitoring stress levels and controlling the resources 
that influence their anxiety is a significant necessity. Principals and deans of medical schools may take steps to reduce student anxiety by providing a stable environment for accurate, high-quality assessment framework as well as student support in the current crisis. In addition, robust online exam platforms are recommended to reduce students' potential stress. This study emphasizes to incorporate various strategies to reform the teaching, learning, evaluation and a reliable exam environment as an essential component to encourage students adopting E-assessment. Further studies are needed to evaluate ways to reduce online exam anxiety among medical students and to provide effective solutions.

\section{List Of Abbreviations}

- COVID-19: Coronavirus disease 2019

- MUMS: Mashhad University of Medical Sciences

- IAU: International Association of Universities

\section{Declarations}

\section{- Ethics approval:}

This study was approved by Mashhad University of Medical Sciences Ethics Committee (IR.MUMS.REC.1399.551). Written informed consent was obtained from all participants. All methods were carried out following relevant guidelines and regulations.

\section{- Consent to participate:}

No applicable for this study

\section{- Consent for publication:}

Not applicable

\section{- Availability of data and material:}

The datasets used and/or analyzed during the current study are available from the corresponding author on reasonable request.

\section{- Competing interests:}

The authors declare that they have no competing interests

\section{- Funding:}

The study was funded by Mashhad University of Medical Sciences, Mashhad, Iran. 


\section{- Authors' contributions:}

All of the authors participated in writing the main manuscript. All of the authors reviewed the manuscript. Haniye Mastour: wrote the study proposal,conducted the idea of the study, software support, supervisor. AmirAli Moodi Ghalibaf: wrote the study proposal, data gathering. Shabnam Niroumand: wrote the study proposal,data analysis, main reviewer of the study.

\section{- Acknowledgements:}

Not applicable

\section{References}

1. Alsaady I, Gattan H, Zawawi A, Alghanmi M, Zakai H. Impact of COVID-19 Crisis on Exam Anxiety Levels among Bachelor Level University Students. Mediterranean Journal of Social Sciences. 2020;11(5):33-.

2. Junaid MAL, Auf Al, Shaikh K, Khan N, Abdelrahim SA. Correlation between Academic Performance and Anxiety in Medical Students of Majmaah University-KSA. JPMA. 2020;2020.

3. Roos A-L, Goetz T, Voracek M, Krannich M, Bieg M, Jarrell A, et al. Test Anxiety and Physiological Arousal: A Systematic Review and Meta-Analysis. Educational Psychology Review. 2020:1-40.

4. Saravanan C, Kingston R, Gin M. Is test anxiety a problem among medical students: a cross sectional study on outcome of test anxiety among medical students? International journal of psychological studies. 2014;6(3):24.

5. Alqudah MA, Ab Rashid R. A REVIEW OF FACTORS CAUSING TEST ANXIETY. Journal of Qualitative Social Sciences. 2020;2(1):1-6.

6. Guo X, Dong Y, Zhao X, Li X, Zhang L. Investigation on students' test anxiety in 461 medical college. China Journal of Health Psychology. 2016;24(12):1877-80.

7. Karthika R, Vijayakumar P, Rawal BS, Wang Y, editors. Secure Online Examination System for elearning. 2019 IEEE Canadian Conference of Electrical and Computer Engineering (CCECE); 2019: IEEE.

8. Stowell JR, Bennett D. Effects of online testing on student exam performance and test anxiety. Journal of Educational Computing Research. 2010;42(2):161-71.

9. Zagury-Orly I, Durning SJ. Assessing open-book examination in medical education: The time is now. Medical Teacher. 2020:1-2.

10. Liu Y, Pan H, Yang R, Wang X, Rao J, Zhang X, et al. Test anxiety and emotion regulation among undergraduate medical students in China: the mediating role of psychological resilience. 2020.

11. Arbabisarjou A, Zare S, Shahrakipour M, Ghoreishinia G. Analyzing test anxiety among medical sciences students of Zahedan in 2015. International Journal of Medical Research \& Health Sciences. 2016;5(7):334-7. 
12. Yazdani F. Test anxiety and academic performance in female nursing students. Quarterly Journal of Nursing Management. 2012;1(1):58-47.

13. Hilburg R, Patel N, Ambruso S, Biewald MA, Farouk SS. Medical Education during the Coronavirus Disease-2019 Pandemic: Learning From a Distance. Advances in Chronic Kidney Disease (ACKD). 2020. Article in Press: 1-6. https://doi.org/10.1053/j.ackd.2020.05.017.

14. Pahwa B, Goyal S, Srivastava K, Saldanha D, Bhattacharya D. A study of exam related anxiety amongst medical students. Industrial Psychiatry Journal. 2008;17(1):46-48.

15. Soliman M. Perception of stress and coping strategies by medical students at King Saudi University, Riyadh, Saudi Arabia. Journal of Taibah University Medical Sciences. 2014;9(1):30-35.

16. Simran G, Sangeeta N, Lily W. Evaluation of Examination Anxiety Status and its Associated Factors among First Professional Medical (MBBS) Students. International Journal of Interdisciplinary and Multidisciplinary Studies (IJIMS). 2015;2(8): 1-11.

17. Anwar A, Seger C, Tollefson A, Diachun CAB, Tanaka P, Umar S. Medical education in the COVID-19 era: Impact on anesthesiology trainees. Journal of Clinical Anesthesia 66 (2020) 109949. https://doi.org/10.1016/j.jclinane.2020.109949.

18. Beiter R, Nash R, McCrady M, Rhoades D, Linscomb M, Clarahan M, Sammut S. The prevalence and correlates of depression, anxiety, and stress in a sample of college students. Journal of Affective Disorders. 2015;173:90-96. https://doi.org/10.1016/j.jad.2014.10.054.

19. Gross M, Latham D. Attaining information literacy: An investigation of the relationship between skill level, self-estimates of skill, and library anxiety. Library \& Information Science Research. 2007; 29(3): 332-353.

20. Saravasan C, Kingston R, Gin M. Is test anxiety a problem amongst medical students: A cross sectional study on outcome of test anxiety amongst medical students? International journal of psychological studies.2014;6(3):24-31.

21. Quek TTC, Tam WWS, Tran BX, Zhang M, Zhang Z, Ho CSH, Ho RCM. The Global Prevalence of Anxiety among Medical Students: A Meta-Analysis. International Journal of Environmental Research and Public Health. 2019;16(2735):1-18.

22. Dyrbye LN, Thomas MR, Shanafelt TD. Systematic review of depression, anxiety, and other indicators of psychological distress among US and Canadian medical students. Academic Medicine. 2006; 81(4), 354-373.

23. Singh R, Goyal M, Tiwari S, Ghildiyal A, Nattu SM. Effect of examination stress on mood, performance and cortisol levels in medical students. Indian J Physiol Pharmacol. 2012;56(1):48-55.

24. De Pablo J, Subira S, Martin MJ, de Flores T, Valdes M. Examination associated anxiety in students of medicine. Acad Med. 1990;65(11):706-7.

25. Kharche JS, Pranita A, Phadke AV, Joshi AR. Evaluation of examination stress in 1st year M.B.B.S. students. NJIRM. 2012;3(5):27-31.

26. Ishtiaq S, Khan M, Shaheen A, Mansoor S. Prevalance of study related anxiety among female medical students. ISRA Medical Journal. 2013;5(2):110-115. 
27. Latas M, Pantic M, Obradovic D. Analysis of test anxiety in medical students. Medicinski pregled. 2010;63(11-12):863-866. DOI: 10.2298/MPNS1012863L.

28. Vatankhah M, Kalani N, Rayat Dost E, Abiri S. Investigation of Anxiety Test in Medical Students of Jahrom University of Medical Sciences: A Cross-sectional, Descriptive Study. J Biochem Tech. 2018;Special Issue(2):114-118.

29. Jadoon NA, Yaqoob R, Raza A, Shehzad MA, Zeshan SC. Anxiety and depression among medical students: a cross-sectional study. JPMA. The Journal of the Pakistan Medical Association. 2010; 60(8), 699-702.

30. Darabi M, Aivazi AA, Gholami-Parizad E, Ghazanfari Z, Imanzad M. Test anxiety among Ilam UMS'students, 2012. Advances in Nursing \& Midwifery. 2013;23(82),1-7.

31. Tsegay L, Shumet S, Damene W, Gebreegziabhier G, Ayano G. Prevalence and determinants of test anxiety among medical students in Addis Ababa Ethiopia. BMC Medical Education. 2019;19(1):423. https://doi.org/10.1186/s12909-019-1859-5.

32. Cipra C, Muller-Hilke B. Testing anxiety in undergraduate medical students and its correlation with different learning approaches. PLOS ONE. 2019; 14(3): e0210130. https://doi.org/10.1371/journal.pone.0210130.

33. Afzal H, Afzal S, Siddique SA, Naqvi SA. (2012). Measures used by medical students to reduce test anxiety. JPMA. The Journal of the Pakistan Medical Association, 62(9), 982-986.

34. Zhang $\mathrm{N}$, Henderson CNR. Test anxiety and academic performance in chiropractice student. J Chirop Educ. 2014;28(1):2-8.

35. Rehman F, Saeed I, Zubairi MU, Umar M, Shahzad A, Rehman A. Influencing Factors of Examination Anxiety among Medical Students in Lahore-Pakistan. P J M H S. 2020;14(1):175-178.

36. Inam SN, Saqib A, Alam E. Prevalence of anxiety and depression among medical students of private university. JPMA. The Journal of the Pakistan Medical Association. 2003;53(2),44-47.

37. Elsalem L, Al-Azzam N, Jum'ah AA, Obeidat N, Sindiani AM, Kheirallah KA. Stress and behavioral changes with remote E-exams during the Covid-19 pandemic: A cross-sectional study among undergraduates of medical sciences. Annals of Medicine and Surgery 60. 2020: 271-279. https://doi.org/10.1016/j.amsu.2020.10.058.

38. Lyndon MP, Strom JM, Alyami HM, Yu TC, Wilson NC, Singh PP, Lemanu DP, Yielder J, Hill AG. The relationship between academic assessment and psychological distress among medical students: A systematic review. Perspectives on Medical Education. 2014;3(6):405-418. DOI 10.1007/s40037-0140148-6.

39. Sugiura G, Shinada K, Kawaguchi Y. Psychological well-being and perceptions of stress amongst Japanese dental students. European Journal of Dental Education. 2005;9(1):17-25.

40. Farooqi YN, Ghani R, Spielberger CD. Gender differences in test anxiety and academic performance of medical students. International journal of psychology and behavioral sciences. 2012;2(2):38-43.

41. Blanch DC, Hall JA, Roter DL, Frankel RM. Medical student gender and issues of confidence. Patient Educ Couns. 2008;72(3):374-81. 
42. Al-Sowygh ZH. Academic distress, perceived stress and coping strategies among dental students in Saudi Arabia. The Saudi dental journal. 2013;25(3):97-105.

43. Rezazadeh M, Tavakoli M. Investigating the Relationship among Test Anxiety, Gender, Academic Achievement and Years of Study: A Case of Iranian EFL University Students. English Language Teaching. 2009;2(4):68-74.

44. Golmirzaei J, Paknahad A, Sharafi M. Prevalance of exam related anxiety of medical students among basic sciences. Comprehensive Journal of Science and medicine. 2014;1 (1):30-36.

45. Ibrahim AK, Kelly SJ, Adams CE, Glazebrook C. A systematic review of studies of depression prevalence in university students. Journal of Psychiatric Research. 2013;47(3):391-400.

46. Gabanbarpur Z, Eisazadeh J. Effectiveness of teaching time management strategies on student's anxiety and their academic performance. International journal of psychology and behavioral science. 2013;2(1):51-58.

47. Hashim Z, Miller A, Fahim N. The exam skills workshop as formative assessment for medical students. International Journal of Collaborative Research on Internal Medicine and Public Health. 2012;4(5):578-588.

48. Hodges C, Moore S, Lockee B, Trust T, Bond A. The Difference between Emergency Remote Teaching and Online Learning, EDUCAUSE Review. March 27, 2020.

https://er.educause.edu/articles/2020/3/the-difference-between-emergency-remote-teaching-andonline-learning.

49. OECD (2020). Remote online exams in higher education during the COVID-19 crisis. 2020. doi:https://doi.org/10.1787/f53e2177-en.

50. Alruwais N, Wills G, Wald M. Advantages and Challenges of Using e-Assessment. International Journal of Information and Education Technology. 2018;8(1):34-37. https://doi.org/10.18178/ijiet.2018.8.1.1008.

51. Wibowo S, Grandhi S, Chugh R, Sawir E. A pilot study of an electronic exam system at an Australian university. Journal of Educational Technology Systems. 2016;45(1):5-33. https://doi.org/10.1177/0047239516646746.

52. Bernik I, Jereb E. Students' readiness for electronic examinations. Proceedings of the 5th WSEAS International Conference on Education and Educational Technology, Tenerife, Canary Islands, Spain, December 16-18, 2006. https://citeseerx.ist.psu.edu/viewdoc/download? doi=10.1.1.506.7030\&rep=rep1\&type=pdf.

53. Butler-Henderson K, Crawford J. A systematic review of online examinations: A pedagogical innovation for scalable authentication and integrity. Computers \& Education 159 (2020) 104024. https://doi.org/10.1016/j.compedu.2020.104024.

54. Crawford J, Butler-Henderson K, Rudolph J, Malkawi B, Glowatz M, Burton R, Magni PA, Lam S. COVID-19: 20 countries' higher education intra-period digital pedagogy responses. Journal of Applied Learning and Teaching. 2020;3(1): 9-28. https://doi.org/10.37074/jalt.2020.3.1.7. 